Published in final edited form as:

Anal Chem. 2018 September 04; 90(17): 10340-10349. doi:10.1021/acs.analchem.8b02153.

\title{
On the Measurement of Energy Dissipation of Adhered Cells with the Quartz Microbalance with Dissipation Monitoring
}

\author{
Amir Monemian Esfahani ${ }^{1}$, Weiwei Zhao ${ }^{1}$, Jennifer Y. Chen ${ }^{2}$, Changjin Huang ${ }^{3}$, Ning $\mathrm{Xi}^{4}$, \\ Jun $\mathrm{Xi}^{2,{ }^{*}}$, Ruiguo Yang ${ }^{1, *}$ \\ ${ }^{1}$ Department of Mechanical and Materials Engineering, University of Nebraska-Lincoln, Lincoln, \\ NE 48824, United States \\ 2Department of Chemistry, Drexel University, Philadelphia, Pennsylvania 19104, United States \\ ${ }^{3}$ Department of Biomedical Engineering, Carnegie Mellon University, Pittsburgh, PA 15213, \\ United States \\ ${ }^{4}$ Department of Industrial and Manufacturing Systems Engineering, The University of Hong Kong, \\ HK, China
}

\begin{abstract}
We previously reported the finding of a linear correlation between the change of energy dissipation $(\Delta D)$ of adhered cells measured with the quartz crystal microbalance with dissipation monitoring (QCM-D) and the level of focal adhesions of the cells. To account for this correlation, we have developed a theoretical framework for assessing the $\Delta D$-response of adhered cells. We rationalized that the mechanical energy of an oscillating QCM-D sensor coupled with a cell monolayer is dissipated through three main processes: the interfacial friction through the dynamic restructuring (formation and rupture) of cell-extracellular matrix (ECM) bonds, the interfacial viscous damping by the liquid trapped between the QCM-D sensor and the basal membrane of the cell layer, and the intracellular viscous damping through the viscous slip between the cytoplasm and stress fibers as well as among stress fibers themselves. Our modeling study shows that the interfacial viscous damping by the trapped liquid is the primary process for energy dissipation during the early stage of the cell adhesion, whereas the dynamic restructuring of cell-ECM bonds becomes more prevalent during the later stage of the cell adhesion. Our modeling study also establishes a positive linear correlation between the $\Delta D$-response and the level of cell adhesion quantified with the
\end{abstract}

\footnotetext{
*To whom correspondence should be addressed. ryang6@unl.edu, jx35@drexel.edu. SUPPORTING INFORMATION

The supporting information is available free of charge on the ACS Publications website:

S1: Bond transition equations

S2: Force in the adhesion bond

S3: Derivation of equation of motion

S4: Calculation of damping ratio

S5: Numerical simulation

S6: Radial dependence of the shear amplitude of the sensor oscillation

S7: Experimental methods

S8: Parameters of computation

S9: Reference

COMPETING OF INTERESTS

The authors declare no conflict of interest.
} 
number of cell-ECM bonds, which corroborates our previous experimental finding. This correlation with a wide well-defined linear dynamic range provides a much needed theoretical validation of the dissipation monitoring function of the QCM-D as a powerful quantitative analytical tool for cell study.

\section{Graphical Abstract}

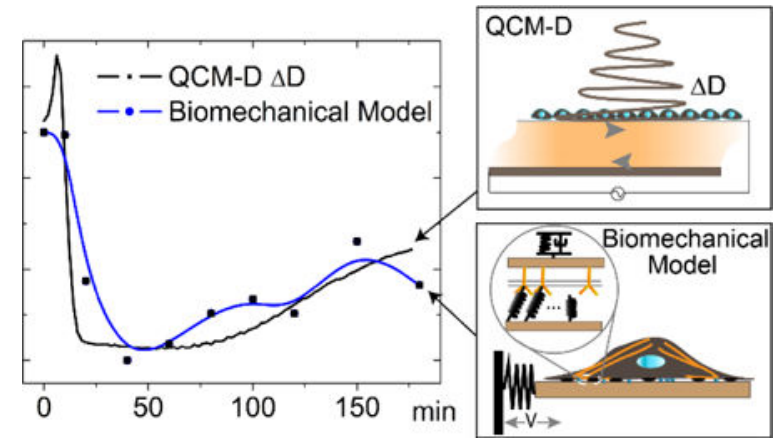

\section{Keywords}

quartz crystal microbalance; energy dissipation; cell adhesion; cell mechanics; biomechanical model; biosensing

\section{INTRODUCTION}

The quartz crystal microbalance with dissipation monitoring (QCM-D) is a mechanical sensing device that measures mechanical and mass changes of an adlayer on the surface of a QCM-D sensor. When an alternating voltage is applied to a QCM-D sensor which is made of a disk-shaped AT-cut quartz crystal sandwiched between a pair of electrodes (Figure 1A), the piezoelectric quartz crystal generates a shear-mode oscillation resulting from the difference in the lateral displacements along its top and bottom surfaces (Figure 1B). The frequency of the oscillating sensor disk is extremely sensitive to the mass coupled to the surface of the sensor disk. If such a mass is small and rigid, the change in mass can be determined according to the Sauerbrey relationship based on the change in resonance frequency of the oscillating sensor crystal ${ }^{1}$. When the mass is soft and/or submerged in liquid medium, the Sauerbrey relationship becomes invalid. The damping of the oscillating QCM crystal can be characterized with the change of energy dissipation, $\Delta D$, a dimensionless quantity that is defined as, $D=\frac{E_{\text {dissipated }}}{2 \pi E_{\text {stored }}}$, where $E_{\text {dissipated }}$ is the energy dissipated during one cycle of oscillation and $E_{\text {stored }}$ is the energy stored in the oscillating sensor disk.

Because of its fine displacement (nanometer scale) and ultra-high oscillation frequency (a fundamental resonance frequency of $5 \mathrm{MHz}$ or higher), the QCM-D is capable of simultaneously measuring real-time changes of resonance frequency $(\Delta f)$ and energy dissipation $(\Delta D)$ of the oscillating sensor disk with high sensitivity and temporal resolution. Such capability has been extended to applications ranging from chemical $^{2}$, physical ${ }^{3}$, 
biological ${ }^{4,5}$, to biomedical research ${ }^{6}$. In particular, the viscoelasticity and absorptions of polymers ${ }^{7,8}$ and biomolecules such as proteins ${ }^{9}$, DNA ${ }^{10,11}$ and lipids ${ }^{12}$ have been examined. In recent years, QCM-D has been successfully applied to cell biology studies ${ }^{13-21}$. As a real-time label-free sensing approach, it has been particularly effective in examining cell adhesions. In such studies, the time-dependent change of resonance frequency $(\Delta f)^{22-27}$ is typically used as a marker for monitoring the adhesion of cells onto the surface of a QCM-D sensor and providing kinetic information of the adhesion process. Because of the viscoelastic nature and the aqueous surrounding of the cell, the $\Delta f$-response is not directly proportional to the change of cell mass $(\Delta m)$. Thus, such $\Delta f$-based measurement is more a qualitative assessment of the cell adhesion. The time-dependent change of energy dissipation $(\Delta D)^{26-32}$ has been used to complement the measurement of the $\Delta f$-response by providing information on the intrinsic structural and mechanical properties of adherent cells ${ }^{29,33-38}$. However, the dissipative processes that are responsible for the measured $\Delta D$-response of adherent cells remains controversial ${ }^{27,28,30,39,40}$.

In our studies of cell adhesion ${ }^{39,40}$, we have found a linear correlation between the $\Delta D$ response of adhered cells and their areal density of focal adhesions. Focal adhesions are cellular protein complexes that are primarily responsible for linking the intracellular environment to the extracellular matrix (ECM) and the substratum ${ }^{41,42}$. More specifically, the ECM on the substrate binds to integrin receptors on the cell membrane. The resulting ECM-integrin linkages lead to the formation of focal adhesions that interact with intracellular cytoskeleton. Since the area of focal adhesions is quantitatively related to the mechanical strength of the cell adhesion ${ }^{43-46}$, we used the $\Delta D$-response as a quantitative measure of the strength of the cell adhesion in examining epidermal growth factor (EGF)induced de-adhesion of MCF10A cells ${ }^{39,40}$. Such quantitative assessment allowed us to identify a series of sequential events in the EGF-induced cell de-adhesion process which consists of a rapid de-adhesion, transition, and re-adhesion.

To further validate this correlation between the $\Delta D$-response and the areal density of focal adhesions of adhered cells, we have developed a theoretical framework for assessing dissipation of the mechanical energy of an oscillating QCM-D sensor coupled with a cell monolayer. Some of the existing quantitative models for describing the physical behavior of the QCM-D were constructed based on equivalent circuit and impedance analysis ${ }^{27,47}$. An equivalent circuit which models the electrical characteristics of a quartz crystal resonator in contact with a viscoelastic material, i.e. the cultured cell layer, is capable of providing the change in the viscoelastic property of the material based on the recorded impedance data. A different approach developed by Voinova and coworkers ${ }^{48}$, based on continuum mechanics, models the mechanical wave propagation through a viscoelastic material covered by a Newtonian fluid. By setting up appropriate boundary conditions, the change in frequency and energy dissipation can be expressed in terms of the physical properties of the viscoelastic thin film and the Newtonian fluid. These and other modeling approaches reviewed by Johannsmann ${ }^{49}$, Kanazawa ${ }^{50}$ and Ellis ${ }^{51}$, usually treat a layer of biomolecules as a static homogenous film. Such treatment, when applied to adherent cells, does not take the dynamic restructuring of cell adhesion into account. Intracellular damping between the cytoplasm and the stress fibers is ignored as well ${ }^{52,53}$. More importantly, current modeling approaches do not consider the complex nature of the interface between the basal region of a 
cell layer and the surface of the QCM-D sensor. This interface not only serves as the physical linkage between the cell layer and the substrate surface, but also is capable of trapping the liquid medium, both of which may cause significant amounts of damping to an oscillating QCM-D sensor ${ }^{28}$.

Considering our experimental finding of the linear correlation between the areal density of focal adhesions and the $\Delta D$-response of adherent cells ${ }^{39,40}$, we expect that the dissipative processes that contribute to the $\Delta D$-response should be those cellular behaviors that are capable of influencing the dynamic restructuring of focal adhesions. These cellular behaviors include those that have been overlooked by the current modeling approaches. Herein, we have developed a biomechanical model for assessing the kinetics of the oscillation of a cell-adhered QCM-D sensor disk by taking into account the dynamic restructuring of the focal adhesion and stress fibers. The model considers the following three primary energy dissipative processes: the interfacial friction between the cell and the sensor disk, the intracellular damping of stress fibers, and the interfacial viscous damping by the liquid trapped between the basal membrane and the sensor disk. We used this model to quantitatively evaluate the contribution of each process to the $\Delta D$-response and examine the relationship between the $\Delta D$-response and the cell adhesion.

\section{MODEL DEVELOPMENT}

\section{Rationalization}

The $\Delta D$-response is known to measure the loss of the mechanical energy of an oscillating QCM-D sensor disk caused largely by the interfacial friction and internal friction of the adsorbate ${ }^{54}$. In cell studies, the interfacial friction lies at the interface between the adhered cell layer and the oscillating QCM-D sensor disk. At the molecular level, we consider the interfacial friction as a result of dynamic restructuring of the integrin-ECM bonds (i.e., integrin-ECM linkages, cell-ECM bonds, or adhesion bonds): ECM ligands on the sensor surface continuously engage to or dissociate from integrin receptors on the basal membrane of the cell when they are in close vicinity. Integrin-ECM bonds are weak noncovalent interaction which has a limited lifetime. Under zero force, a large number of integrin-ECM bonds remain close to equilibrium between engagement and dissociation ${ }^{55}$. Such equilibrium will be tilted more toward dissociation upon application of an external force which lowers the energy barrier for the bond dissociation ${ }^{56}$. Dynamic restructuring of the adhesion bonds in response to low extracellular tension has been previously demonstrated experimentally at the molecular level ${ }^{57,58}$.

In our model, successful engagement of multiple integrin-ECM bonds enables the sensor disk and the cell layer to be physically coupled and oscillate synchronously, the characteristics of a "stick" regime. The oscillation of the sensor disk stretches the integrinECM bonds and transforms part of the mechanical energy of the oscillating sensor disk to the potential energy of the adhesion bonds. When an adhesion bond elongates to the extent that the endured mechanical energy of the bond exceeds its bond dissociation energy, the ECM ligand will disengage from the integrin receptor, i.e., bond rupture, and the stored energy of the sensor disk will be dissipated. The rupture of a large number of adhesion bonds will perturb the synchronized oscillation and shift the mechanical regime of the 
QCM-D sensor from the "stick" regime to a "slip" regime. In this work, we applied Bell's model, a popular theoretical framework for analysis of the kinetics of reversible adhesion of the cell ${ }^{59,60}$, to examine the biomechanics and energy conversion that govern such stick-slip transition during the dynamic restructuring of adhesion bonds of adhered cells.

We also consider that the stick-slip transition occurs between the oscillating QCM-D sensor disk and the liquid medium trapped between the sensor disk and the basal region of the adhered cell layer. This transition which has been previously examined theoretically ${ }^{61,62}$ and experimentally ${ }^{63}$ is known to cause the loss of the mechanical energy of the oscillating sensor disk and give rise to the $\Delta D$-response ${ }^{64,65}$. A further characterization of this transition based on the $\Delta D$-response is described in Supporting Information (S4 and table S1). The internal friction of the adhered cell layer in the form of intracellular viscous damping is the third dissipative process examined in this study. We specifically focused on the intracellular viscous slip between stress fibers and the cytoplasm, and among stress fibers themselves. These cellular behaviors are closely associated with the dynamic restructuring of the cytoskeleton of the cells, which dictates the viscoelasticity of the cell layer and can influence the $\Delta D$-response ${ }^{14,38}$. The intracellular viscous slip is mechanically coupled to the stick-slip transition at the cell-substrate interface through the stress fiber-integrin-ECM linkages and can thus be influenced by the oscillation of the QCM-D sensor disk. We applied the viscoelastic Voigt element, i.e., a spring-dashpot combination in parallel, to examine this dissipative process.

In summary, our biomechanical model takes into account three intrinsic biomechanical processes involving cells that are adhered to the QCM-D sensor disk. All three processes have been previously established experimentally and are capable of damping the oscillation of the sensor disk through energy dissipation.

\section{Dynamics of the oscillating sensor disk}

In our biomechanical model, we treated the QCM-D sensor disk as a harmonic oscillator ${ }^{65}$ that is driven by an anchoring spring horizontally as shown in Figure 1C. This harmonic oscillator retains all the important characteristics of the QCM-D, such as the size and mass density of the sensor disk, the oscillation frequency, and the distribution profile of the oscillation amplitude ${ }^{65}$. The dynamics of the oscillation of the sensor disk can be defined by the following equation:

$$
m \ddot{x}+\eta_{1} \dot{x}+F_{P}+K x=0
$$

where $m$ is the mass of the sensor disk; $\eta_{I}$ is the viscous coefficient for the trapped liquid medium; $x$ is the index of the sensor disk in the direction of oscillation; $K$ is the spring constant of the anchoring spring that drives the oscillation of the sensor disk. Therefore, $m \ddot{x}$ denotes the inertial force resulting from the acceleration of the sensor disk and $K x$ is the restoring force in the spring. The physical interaction between the cell layer and the sensor disk is characterized with the interfacial viscous damping $\eta_{1} \dot{x}$ by the liquid medium and with the peeling force $\boldsymbol{F}_{p}$ by the cells through integrin-ECM bonds. The peeling force $\boldsymbol{F}_{P}$ 
originates from the sum of adhesive forces $(F)$ in the elongated integrin-ECM bonds along the opposite direction of oscillation.

The energy dissipation measurement with the QCM-D, defined based on energy dissipation factor $(D)$, can be inferred from the loss of the mechanical energy of the sensor disk due to the damping effect for a given period during the oscillation in the following equation,

$$
D=\frac{E_{\text {dissipated }}}{2 \pi E_{\text {stored }}}=\frac{E_{\text {in }}-E_{\text {out }}}{2 \pi E_{\text {in }}} .
$$

where the stored energy $E_{\text {stored }}$ of the system originates from the initial energy input: $E_{\text {in }}=\frac{1}{2} K A_{0}^{2}$, where $A_{0}$ is the initial oscillation amplitude. The dissipated energy $E_{\text {dissipated }}$ is defined as the difference between the input energy and the output energy, which is equal to the sum of the kinetic energy of the sensor disk and the potential energy of the anchoring spring: $E_{\text {out }}=\frac{1}{2} m \dot{x}^{2}+\frac{1}{2} K x^{2}$.

\section{Dynamics of cell adhesion}

In our biomechanical model, we treated integrin-ECM bonds as an ensemble of elastic springs that connect the cell and the moving sensor disk ${ }^{66}$ as shown in Figure 1D. Each bond resides in one of the two states: a closed bond state when an integrin is fully engaged with ECM, or an open bond state when the integrin is disengaged (ruptured) from ECM. Thus, the peeling force $F_{p}$ can be derived from the sum of the adhesive forces $(F)$ in all of closed integrin-ECM bonds projected in the opposite direction of oscillation $(-\mathrm{x})$. Assuming that all the integrin-ECM bonds distribute uniformly along the basal membrane and contribute equally to the peeling force,

$$
F_{P}=\sum_{i=1}^{N} q_{i} F_{i}^{x}
$$

where $i$ is the bond index and $N$ is the total number of integrin receptors at the basal membrane that involve in the formation of integrin-ECM bonds; $F_{i}^{x}$ is the adhesive force in the $i$ th bond, $F_{i}$, projected in the $-\mathrm{x}$ direction; $q_{i}$ is the state of the bond with $\mathrm{q}_{\mathrm{i}}=\left\{\begin{array}{ll}0 & \text { open bond } \\ 1 & \text { closed bond }\end{array}\right.$.

The stochastic transition between a closed bond and an open bond can be defined by:

$q_{i}(t+\Delta t)=q_{i}(t)-q_{i}(t) H\left(-\xi_{i}+\Delta t k_{\mathrm{off}^{v}} v\right)+\left[1-q_{i}(t)\right] H\left(-\xi_{i}+\Delta t k_{\mathrm{on}}(1-v)\right)$,

where $H(\cdot)$ is the Heaviside step function. $\xi_{i}$ is a random number belonging to [0,1], which introduces the stochastic component to bond transition ${ }^{66} ; k_{o n}$ and $k_{\text {off }}$ are bond formation 
and dissociation rate constants, respectively; $v=\frac{N_{b}}{N}$ is defined as the closed bond ratio, where $N_{b}$ is the number of closed bonds and $N$ is the total number of integrin receptors ${ }^{59}$. A detailed derivation for the transition equation can be found in Supporting Information (S1).

Dynamic restructuring of an integrin-ECM bond occurs when the bond undergoes a dynamic transition between the open and closed states ${ }^{57}$. Such transition can be influenced by an applied load, which reduces the barrier height of bond dissociation energy and increases the rate of bond rupture. Thus, the rate constant of dissociation of the ith bond, under the influence of its adhesive force, can be determined from the following equation:

$$
k_{\mathrm{off}}(i)=k_{o f f}^{0} \exp \left(\frac{F_{i} \Delta L_{i}}{K_{B} T}\right),
$$

where $F_{i}$ is the adhesive force of the $i$ th bond; $\Delta L_{i}$ is the length of extension of the $i$ th bond; and $K_{B} T$ is the thermal energy. $k_{o f f}^{0}$ is the initial rate constant for bond dissociation ${ }^{59}$. On the other hand, the rate of bond formation depends on the velocity of the sensor disk $V$ as follows:

$$
k_{\text {on }}=\left\{\begin{array}{l}
k_{o n}^{0} V \leq V_{c} \\
0 \quad V>V_{c}
\end{array},\right.
$$

where $k_{o n}^{0}$ is the initial rate constant of bond formation and $V_{\mathcal{c}}$ is the critical velocity ${ }^{67}$. The bond formation is prohibited when the velocity of the sensor disk $V$ exceeds $V_{c}$. The forces in relation to distances in a closed bond are illustrated in Figure $1 \mathrm{E}$ with $F_{i}$ representing the bond force in the $i$ th adhesion bond, and $F_{i}^{x}$ as the peeling force $F_{P}$ in the $-\mathrm{x}$ direction and $F_{P}=\sum_{i=1: N} F_{i}^{x} \cdot L_{i}$ is the length of the $i$ th bond and $L_{0}$ is the natural length of an adhesion bond. The geometrical relationship, the force balance and the equation of motion in relation to the stress fiber are detailed in Supporting Information (S2 and S3).

The loss of mechanical energy of the sensor disk due to bond rupture can be determined as follows: $E_{b}=\sum_{i=1}^{N} q_{i}(t)\left(1-q_{i}(t+\Delta t)\right) F_{i} \Delta l_{i}{ }^{68}$. This expression describes the loss of the mechanical energy of the oscillating QCM-D sensor disk while adhesion bonds undergo transition from closed states to open states. Meanwhile, the energy loss due to interfacial viscous damping by the liquid medium trapped between the cell membrane and the sensor disk can be determined as follows: $E_{v}=\int_{0}^{\Delta t} \eta_{l} \dot{x}^{2} d t$. The coefficient, $\eta_{l}$, was determined experimentally with a QCM-D sensor disk submerged in an aqueous medium detailed in Supporting Information (S4). 


\section{Intracellular dynamics}

In our biomechanical model, we considered the intracellular viscous damping by stress fibers including the viscous slip between stress fibers and the cytoplasm and among stress fibers themselves as the main intracellular processes that contributes to the dissipation of the mechanical energy of the oscillating sensor disk. The stress fibers that are involved in such intracellular dissipative processes are physically linked to the sensor disk through the integrin-ECM linkage. The tensional force in these stress fibers is therefore balanced by the adhesive force $(F)$ in the integrin-ECM bonds generated during the oscillation of the sensor disk. Because of the viscoelastic character of stress fibers, we applied a lumped model with the viscoelastic Voigt element, i.e., a spring-dashpot combination in parallel, to describe this force balance:

$$
\sum_{i=1}^{N} q_{i} F_{i}=\kappa_{s f} \Delta L_{s f}+\mu_{s f} \Delta \dot{L}_{s f}
$$

where $\kappa_{s f}$ and $\mu_{s f}$ are the elastic and damping coefficient of the stress fiber; $\Delta L_{s f}$ and $\Delta \dot{L}_{s f}$ are the extension and extension rate of the stress fibers, respectively ${ }^{69}$. Thus, the sum of the adhesive forces from all the integrin-ECM bonds is equal to the elastic component $\kappa_{s f} \Delta L_{s f}$ and viscous component $\mu_{s t} \Delta \dot{L}_{s f}$ of the stress fibers. Eq. (7) is solved in conjunction with Eq. (1) to determine extension of the stress fiber $\Delta L_{s f}$, which was used to determine the loss of the mechanical energy of the oscillating QCM-D sensor disk caused by the intracellular friction as follows: $E_{s f}=\sum_{i=1}^{N} q_{i} F_{i} \Delta L_{s f}$. All calculations were performed numerically with a MATLAB program and the detailed simulation procedures are provided in Supporting Information (S5 and S6).

\section{RESULTS}

\section{Dynamics of the oscillating sensor disk and kinetics of the adhesion bonds}

The QCM-D sensor disk was modeled as a harmonic oscillator that was driven horizontally by an anchoring spring ${ }^{65}$. When a cell adheres to a sensor disk, focal adhesions of the cell allow the cell to establish a physical connection extracellularly with the sensor disk through integrin-ECM bonds and intracellularly with the cytoskeleton through stress fibers. Such physical connection provides the structural basis for a mechanical coupling that causes damping to the oscillation of the sensor disk and diminishes the amplitude of oscillation over time. Figure 2 shows the dynamics of oscillation of the sensor disk and the kinetics of dynamic restructuring (i.e., formation and rupture) of the integrin-ECM bonds at a given initial displacement of $1 \mathrm{~nm}$ for a simulation time of $5 \mu \mathrm{s}$. Both the displacement and velocity diminish over time from the respective maxima as indicated by the differential displacement and velocity between a damped oscillation and an undamped oscillation (Figure 2A). The damping produces a dissipation factor of $D=150.8 \times 10^{-6}$, calculated by dividing the energy loss shown in Figure 2A to the initial energy from Figure 2B with Eq. (2). Note that the bond number used for the simulation is $\mathrm{N}=10^{10}$. 
The spontaneous bond formation and rupture of integrin-ECM bonds can be greatly influenced by the relative motion between the sensor disk and the cell ${ }^{66,69}$. The rate of bond formation, indicated by the time-dependent change of the closed bond ratio, is modulated by the change of the relative velocity ( $V$ ) between the cell and the oscillating sensor disk (Figure 2B, blue line), which shows a biphasic pattern (Figure 2C). In phase $\mathrm{P}_{1}$ where $V$ $<V_{c}$, the closed bond ratio $v$ climbs rapidly to its peak value $\left(v_{\max }\right)$ of around 0.57 , indicating an overall increase of bond formation over bond rupture. In phase $\mathrm{P}_{2}$ where $V$ $>V_{c}$, bond formation comes to a halt and the closed bond ratio $v$ is dominated by bondrupture events as indicated by a gradual decrease in $v$ from $v_{\max }$ to the minimum $\left(v_{\min }\right)$ around 0.09 . This relationship between the rate of bond formation and the velocity of the oscillating sensor disk is governed by the Bell's model ${ }^{59}: k_{o f f}=k_{o f f}^{0} \exp \left(\frac{F_{i} \Delta L_{i}}{k_{B} T}\right)$.

\section{The dissipative processes of the mechanical energy of the oscillating sensor disk}

We attribute the loss of the mechanical energy of the oscillating QCM-D sensor disk to three main processes: the interfacial friction through the dynamic restructuring (formation and rupture) of the cell-ECM bonds, the interfacial viscous damping by the trapped liquid and the intracellular viscous damping through the viscous slip of the stress fibers and the cytoplasmic material. Among these processes, the energy dissipated by the interfacial viscous damping of the trapped liquid during each oscillation cycle is slightly higher in magnitude with a $\pi / 2$ phase shift than that by the bond rupture. In comparison, the amount of energy dissipated by the intracellular viscous damping is two orders of magnitude less than that by the interfacial viscous damping of the trapped liquid (note: evaluated at bond number $\mathrm{N}=10^{10}$ ) (Figure 3). Such relationship observed during each oscillation cycle remains relatively the same over an extended period of $5 \mu$ s (Figure 3). In summary, the interfacial friction and interfacial viscous damping are largely responsible for the loss of the mechanical energy of the QCM-D sensor. Meanwhile, the intracellular viscous damping contributes very little to the loss of the energy and its contribution can therefore be considered virtually negligible.

In Figure 3, a stacked-column chart is used to compare the total energy dissipated in these three processes to the loss of the mechanical energy of the oscillating sensor disk at a randomly selected time point $(1 \mu \mathrm{s})$. The dissipated energy $\left(E_{b}\right.$ and $\left.E_{V} E_{s f}\right)$ from each of these three processes was determined with the use of the corresponding equations in sections 2.3 and 2.4; whereas the loss of the mechanical energy of the sensor disk was determined based on the difference between the energy input $\left(E_{\text {in }}\right)$ and output $\left(E_{\text {out }}\right)$ of the sensor disk described in section 2.2. The sum of the energies dissipated through these three processes equals the loss of the mechanical energy of the oscillating QCM-D sensor disk. This result validates these three processes as the main energy dissipative processes in our biomechanical model.

\section{Correlation between the dissipated energy and the number of adhesion bonds}

In Figure 4A, the simulated data for the loss of the mechanical energy of the oscillating sensor disk through each of the three dissipative processes was plotted as a log function of the number of adhesion bonds. The result indicates that the energy dissipation caused by the 
interfacial viscous damping of the trapped liquid is virtually independent of the bond number. Assuming cell-ECM bonds do not possess any volume, the change in the volume of the trapped liquid upon the change of bond numbers is therefore negligible. Thus, the energy loss through this dissipative process depends exclusively on the velocity profile of each oscillation cycle. On the other hand, the energy dissipated through the dynamic restructuring (formation and rupture) of cell-ECM bonds shows a clear dependence on the bond number: As the bond number increases, the dissipated energy increases exponentially before leveling off when the bond number exceeds $10^{12}$. Between these two main processes, the interfacial viscous damping by the trapped liquid is clearly the primary cause of the energy dissipation when the bond number is below $5 \times 10^{10}$. However, when the bond number exceeds $10^{11}$, the interfacial friction by the dynamic restructuring of cell-ECM bonds becomes more prevalent. Although the energy dissipation by the intracellular viscous damping also shows a strong dependence of the level of cell adhesion, its contribution never appears close to the levels of the other two processes at any point. This is consistent with the results described in section 3.2 that the intracellular viscous damping among stress fibers and between stress fibers and the cytoplasm is not a major contributor to the loss of mechanical energy of the oscillating QCM-D sensor disk.

In Figure 4B, the simulated energy dissipation $(D)$ responses at both $5 \mathrm{MHz}$ (fundamental frequency) and $15 \mathrm{MHz}$ (third harmonics) were plotted as a log function of the bond number and each plot displays a three-phase profile. In the first phase (LB) where the bond number is below $10^{9}$, both $D$-responses remain virtually constant, resulting from the predominant dissipative process through the interfacial viscous damping by the trapped liquid, evidenced in Figure 4A. It is worth mentioning that the $D$-response at $5 \mathrm{MHz}$ appears at a higher level than that at $15 \mathrm{MHz}$ across the entire range of the bond number. This is due to the fact that the $D$-response is inversely proportional to the oscillation frequency. In the second phase (MB) where the bond number is between $10^{9}$ and $10^{12}$, both $D$-responses exhibit an exponential increase with respect to the bond number. This trend can be attributed to the rapidly increasing contribution from the interfacial friction through the dynamic restructuring of cell-ECM bonds to the overall energy dissipation (Figure 4A). In the third phase (HB) where the bond number exceeds $10^{12}$, both $D$-responses appear saturated and essentially remain leveled.

To further establish the correlation between the $D$-response and the bond number, the energy dissipation data at $15 \mathrm{MHz}$ in Figure 4B was replotted with a linear scale in Figure 4C, which shows a quantitative correlation between the $D$-response and the level of cell adhesion quantified with the number of cell-ECM bonds. The correlation was determined by fitting the plot with an exponential function: $D=D_{0} \exp \left(-\frac{B}{B_{0}}\right)+D_{m}$, where $D$ is energy dissipation factor and $B$ is the bond number. $D_{m}=5.12 \times 10^{-4}, D_{0}=-3.64 \times 10^{-4}$ and $B_{0}=9.68 \times 10^{10}$ are fitting parameters. To verify our previous experimental finding of a linear correlation between the $\Delta D$-response and the level of cell adhesion ${ }^{39,40}$, the range of the $D$ response in this plot that can offer a linear correlation was explored: The data points corresponding to the leveled $D$-response at bond numbers of $5 \times 10^{11}$ and higher (in Figure 4C) were removed. The remaining data points were replotted as shown in Figure 4D and fitted with a linear regression function: $D=t B+D_{0}$, where $D$ is the energy dissipation factor 
and $B$ is the bond number. $t=2.09 \times 10^{-15}$ is the slope and $D_{0}=1.57 \times 10^{-4}$ is the initial baseline value of energy dissipation. A goodness of fit, $R^{2}=0.992$, was obtained with this linear regression function. Assuming that the cell-ECM bonds are uniformly distributed over the basal region of the entire cell layer, the $D$-response shown in Figure 4D clearly supports a linear correlation between the $D$-response and the level of cell adhesion quantified with the number of cell-ECM bonds. This result corroborates our previous experimental finding of a linear correlation between the $\Delta D$-response and the level of cell adhesion ${ }^{39,40}$. Surprisingly, this linear correlation remains validate across a wide dynamic range that covers the bond number from $1.0 \times 10^{6}$ up to approximately $1.7 \times 10^{11}$, corresponding to a range of the $D$ response from $150 \times 10^{-6}$ up to approximately $500 \times 10^{-6}$. In practice, however, the effective working range could be narrower due to the instrumentation limitation.

\section{Comparison between the simulation data and the QCM-D data}

We sought to evaluate the effectiveness of our biomechanical model in assessing the EGFinduced de-adhesion of A431 cells using the QCM-D measurement as a benchmark. Previously we used the QCM-D to examine the EGF-induced de-adhesion of MCF10A cells ${ }^{39,40,70}$ with the aid of immunostained vinculin within the focal adhesions. A similar approach was employed in this study: We quantified the size/relative fluorescence intensity (RFU) of vinculins at various time points based on the areal density of focal adhesions of EGF-treated A431 cells shown in Figure 5A (the experimental methods are detailed in S7). The quantitation result was summarized in Figure 5B, which reveals a time-dependent change of cell adhesion: an initial rapid de-adhesion ( 0 to $40 \mathrm{~min}$ ), followed by a transition period (40 to $60 \mathrm{~min}$ ) and then a final re-adhesion. To simulate a $D$-response plot based on the level of cell adhesion, the $D$-response of $400 \times 10^{-6}$ was set as the value at $0 \mathrm{~min}$ corresponding to a bond number of $1.1 \times 10^{11}$ determined from Figure $4 \mathrm{D}$. The bond numbers at other time points were then determined accordingly based on their corresponding RFU values in relation to the RFU value at $0 \mathrm{~min}$. The resulting bond numbers were used to obtain the $D$-responses at the corresponding time points based on the linear correlation established in Figure 4D. To ensure that the values of RFU and $D$-response could be compared, each of the values was normalized, i.e., was divided by the range covered. For each quantity, the range was taken as the highest value (at $0 \mathrm{~min}$ ) minus the lowest value (QCM-D data at $60 \mathrm{~min}$, simulation data and FA data at $40 \mathrm{~min}$ ). A strong correlation between the QCM-D measurement (experimental data) and the level of cell adhesion (FA data) was shown in Figure 5C. This result with A431 cells is consistent with our previous finding with MCF10A cells, suggesting that this linear correlation between the $\Delta D$-response and cell adhesion may hold true for various types of adherent cells. Furthermore, a strong correlation can be found between the experimental data and the simulated data in the form of the $\Delta D$-response (Figure 5C). This correlation demonstrates the effectiveness of our biomechanical model in examining cell adhesion and validates the theoretical framework of this model. The results described here represent typical experimental and simulation data over many repeats. 


\section{DISCUSSION}

In cell studies, the $\Delta D$-response has mostly been used to characterize the change of the mechanical property of the cells adhered to the QCM-D sensor surface $28,71-74$. The processes that are primarily responsible for the $\Delta D$-response, however, have not been well defined. Change of the membrane structure ${ }^{27}$ and remodeling of actin filaments ${ }^{30}$, two of the major cellular events that can alter the mechanical property of the cell could be two of such energy dissipative processes. Frictional slip between integrin and $\mathrm{ECM}^{57}$, viscous slip among stress fibers, and viscous slip between stress fiber and cytoplasm are known to dissipate mechanical energy ${ }^{52,53}$ during cell adhesion, contraction, and migration ${ }^{75}$. The liquid medium trapped between the cell and the surface of the QCM-D sensor has also been speculated to be responsible for dissipation of the mechanical energy of the QCM-D sensor $^{28}$.

In this work, we have developed a biomechanical model based on the viscoelastic Voigt element and Bell's cell adhesion model, a popular theoretical framework for analysis of the kinetics of reversible adhesion of the cell ${ }^{59,60}$, to quantitatively assess the importance of these possible energy dissipative processes to the $\Delta D$-response. We have found that the interfacial friction through dynamic restructuring (i.e., formation and rupture) of cell-ECM bonds and the interfacial viscous damping by the liquid medium trapped underneath the cell layer are the major dissipative processes that are responsible for the loss of mechanical energy of the cell-adhered QCM-D sensor. Meanwhile, the intracellular viscous damping through the viscous slip between the cytoplasm and the stress fibers as well as among the stress fibers themselves has virtually no impact on the loss of the mechanical energy of the sensor disk. The previously reported effect of disruption of stress fibers with cytochalasin D on the $\Delta D$-response ${ }^{76}$ can be attributed to the downstream effect of such disruption on the cell adhesion since both stress fibers and integrin-ECM bonds are physically linked through focal adhesion complexes. In addition, we have shown that the sum of the dissipated energy from the three dissipative processes equals the loss of the mechanical energy of the oscillating sensor disk during its oscillation. This result validates the key rationale of our biomechanical model which attributes the $\Delta D$-response to these three dissipative processes.

Given that approximately $3 \times 10^{5}$ of A431 cells are needed to constitute a monolayer on a QCM-D sensor (unpublished data) with a bond density of $10^{4}$ to $10^{6}$ per cell ${ }^{77}$, a total number of $10^{9}-10^{11}$ integrin-ECM bonds would be expected for such cell monolayer. Thus a situation with the bond number below $10^{9}$ often occurs during the early stage of the cell adhesion when cells just begin to settle onto the substrate surface without the presence of many mature focal adhesions. Under such situation, the interfacial viscous damping by the trapped liquid appears to be largely responsible for the $\Delta D$-response (Figure 4B). During the later stage of the cell adhesion when the cells adhere strongly to the sensor surface likely with mature focal adhesions, the bond number rises up into a range of $10^{9}-10^{11}$. The interfacial friction through the dynamic restructuring of cell-ECM bonds becomes more prevalent for causing the $\Delta D$-response (Figure 4B).

We have established a positive linear correlation between the energy dissipation response and the number of cell-ECM bonds (Figure 4D). This linear correlation remains validate 
across a wide dynamic range that covers the bond number from $1.0 \times 10^{6}$ up to approximately $1.7 \times 10^{11}$. This suggests that this linear correlation can be applied to the study of the cell adhesion throughout nearly the entire adhesion process. This linear dynamic range also offers a range of $\Delta D= \pm 100 \times 10^{-6}$ for studies involving adhered cells with an initial $D$ of approximately $400 \times 10^{-6}$, which is a sufficient range for the $\Delta D$-response induced by many of exogenous stimulants. When the bond number falls below $10^{6}$, the energy dissipation response no longer exhibits any dependence on bond number and remains virtually constant due to the overwhelming contribution from the viscous damping by the trapped liquid. This situation often occurs in the very beginning of the cell adhesion when a small number of cells just begin to settle onto the substrate surface.

It has been well-documented that the size of the focal adhesion exhibits positive correlations, linear or nonlinear with the cell adhesion strength ${ }^{43-45,78,79}$. Thus, the $\Delta D$-response which correlates with the size of focal adhesions quantified with the areal density of focal adhesion bonds can be used as a quantitative measure of the strength of integrin-ECM bonds. Currently, most of the available technologies for measuring the mechanical strength of adhered cells such as centrifugation, hydrodynamic assays, atomic force microscopy, optical tweezers and traction force microscopy ${ }^{80,81}$ are considered invasive and end-point measurements. The $\Delta D$-based measurement can circumvent such limitations because it is real time and noninvasive and capable of revealing the kinetic information. Interestingly, the in-plane component of the adhesion force is often referred to as the traction force in 2D traction force microscopy, and it is balanced by the tensile forces in the stress fibers when cells are in homeostasis conditions ${ }^{82-84}$. Thus the $\Delta D$-response could potentially provide a quantitation of the overall cellular traction force which may be closely related to the energy loss for the adhered cells during the dynamic restructuring of the adhesion bonds.

Our mechanical model is established based on the physical and biomechanical interaction between the QCM-D sensor disk and the cell. Our model emphasizes the importance of individual biologically relevant processes as well as their collected impact on the energy dissipation measurement. Like the QCM-D, many label-free biosensors are capable of generating real-time, measurable signals by capturing time-dependent cellular events, such as changes in cellular morphology, adhesion, ion distribution, and mass distribution ${ }^{85-87}$. However, due to the complexity of these cellular changes, individual contributing molecular components and their associated cellular processes are often difficult to identify. Thus, the readouts of label-free biosensor signals are commonly referred to as a "black box" $"$. We hope our modeling approach will provide the label-free research community with a capable tool for uncovering what is inside the "black box".

Although our biomechanical model does not account for the cell-cell adhesion, we do not anticipate this to alter the outcome of this work. We reason that the sensing depth of the QCM-D is approximately 100 to $150 \mathrm{~nm}^{89}$, which specifically targets the basal region of the cell. In addition, the interplay of cell-cell and cell-ECM interactions can often be revealed through the cell-ECM measurement. It is worth mentioning that the energy dissipation values and contributions from the three dissipative processes were calculated for a simulation time of $5 \mu$ s with $A_{0}=1 \mathrm{~nm}, f=15 \mathrm{MHz}, \kappa_{b}=0.025 \mathrm{~N} / \mathrm{m}$ and $V_{c}=0.025 \mathrm{~m} / \mathrm{s}$. A few other sets of parameters for $A_{0}, \omega, \kappa_{b}$ and $V_{c}$ were also tested (see S8). Apart from 
some slight variations in the value of energy dissipation from each dissipative process, the parameters used in the simulation do not alter the final outcome and conclusion of the study.

\section{CONCLUSION}

We have developed a theoretical framework to evaluate the effectiveness of the QCM-D for probing cell adhesion. We have found that the dynamic restructuring of cell-ECM adhesion bonds and the viscous damping by the liquid trapped between the basal cell membrane and the QCMD sensor disk are the two processes that are responsible for the energy dissipation response of adhered cells. We have also established a positive linear correlation between the energy dissipation response of adhered cells and the level of cell adhesion. With this work, we hope to provide a fundamental understanding of the QCM-D measurement of adhered cells and offer a theoretical validation of the dissipation monitoring function of the QCM-D as a powerful quantitative analytical tool in cell studies.

\section{Supplementary Material}

Refer to Web version on PubMed Central for supplementary material.

\section{ACKNOWLEDGEMENT}

The authors gratefully acknowledge financial support from the Nebraska Center for Integrated Biomolecular Communication (NCIBC) (NIH National Institutes of General Medical Sciences P20 GM113126) and the U.S. Office of Naval Research (Grant N00014-16-1-2626).

\section{REFERENCES}

(1). Sauerbrey G Verwendung von Schwingquarzen zur Wägung dünner Schichten und zur Mikrowägung. Zeitschrift für Physik A Hadrons and Nuclei 1959, 155, 206-222.

(2). Cheng CI; Chang Y-P; Chu Y-H Biomolecular interactions and tools for their recognition: focus on the quartz crystal microbalance and its diverse surface chemistries and applications. Chem. Soc. Rev 2012, 41.

(3). Urbakh M; Tsionsky V; Gileadi E; Daikhin L In Springer Ser Chem Se, Steinem C; Janshoff A, Eds.; Springer Berlin Heidelberg, 2007, pp 111-149.

(4). Höök F; Kasemo B In Springer Ser Chem Se, 2007, pp 425-447.

(5). Marx KA The quartz crystal microbalance and the electrochemical QCM: Applications to studies of thin polymer films, electron transfer systems, biological macromolecules, biosensors, and cells. Springer Ser. Chem. Sens. Biosens 2007, 5, 371-424.

(6). Hunter AC Application of the Quartz Crystal Microbalance to Nanomedicine. J Biomed Nanotechnol 2009, 5, 669-675. [PubMed: 20201228]

(7). Reddy SM; Jones, J. P; Lewis, T. John Use of combined shear and pressure acoustic waves to study interfacial and bulk viscoelastic effects in aqueous polymeric gels and the influence of electrode potentials. Faraday Discussions 1997, 107, 177-196.

(8). Muramatsu H; Egawa A; Ataka T Reliability of correlation between mass change and resonant frequency change for a viscoelastic-film-coated quartz crystal. J. Electroanal. Chem 1995, 388, 89-92.

(9). Hook F; Kasemo B; Nylander T; Fant C; Sott K; Elwing H Variations in Coupled Water, Viscoelastic Properties, and Film Thickness of a Mefp-1 Protein Film during Adsorption and Cross-Linking: A Quartz Crystal Microbalance with Dissipation Monitoring, Ellipsometry, and Surface Plasmon Resonance Study. Anal. Chem 2001, 73, 5796-5804. [PubMed: 11791547] 
(10). Hook F; Ray A; Norden B; Kasemo B Characterization of PNA and DNA immobilization and subsequent hybridization with DNA using acoustic-shear-wave attenuation measurements. Langmuir 2001, 17, 8305-8312.

(11). Wittung-Stafshede P; Rodahl M; Kasemo B; Nielsen P; Norden B Detection of point mutations in DNA by PNA-based quartz-crystal biosensor. Colloid Surface A 2000, 174, 269-273.

(12). Keller CA; Kasemo B Surface specific kinetics of lipid vesicle adsorption measured with a quartz crystal microbalance. Biophys. J 1998, 75, 1397-1402. [PubMed: 9726940]

(13). Chen JY; Penn LS; Xi J Quartz crystal microbalance: Sensing cell-substrate adhesion and beyond. Biosens. Bioelectron 2018, 99, 593-602. [PubMed: 28830033]

(14). Heitmann V; Reiss B; Wegener J The quartz crystal microbalance in cell biology: Basics and applications. Springer Ser. Chem. Sens. Biosens 2007, 5, 303-338.

(15). Saitakis M; Gizeli E Acoustic sensors as a biophysical tool for probing cell attachment and cell/ surface interactions. Cell. Mol. Life Sci. 2011, 1-15.

(16). Wegener J; Janshoff A; Steinem C The quartz crystal microbalance as a novel means to study cell-substrate interactions In situ. Cell Biochem. Biophys 2001, 34, 121-151. [PubMed: 11394439]

(17). Dixon MC Quartz crystal microbalance with dissipation monitoring: Enabling real-time characterization of biological materials and their interactions. J. Biomol. Tech 2008, 19, 151158. [PubMed: 19137101]

(18). Şeke Ş; Elçin YM In Biological and Medical Sensor Technologies, Iniewski K, Ed.; CRC Press, 2012, pp 105-124.

(19). Marx KA Quartz Crystal Microbalance: A Useful Tool for Studying Thin Polymer Films and Complex Biomolecular Systems at the Solution-Surface Interface. Biomacromolecules 2003, 4, 1099-1120. [PubMed: 12959572]

(20). Cavic BA; Thompson M; Hayward GL Acoustic waves and the study of biochemical macromolecules and cells at the sensor-liquid interface. Analyst 1999, 124, 1405-1420. [PubMed: 10746300]

(21). Xi J; Chen JY; Garcia MP; Penn LS Quartz Crystal Microbalance in Cell Biology Studies. J Biochip Tissue Chip 2013, S5.

(22). Lord MS; Modin C; Foss M; Duch M; Simmons A; Pedersen FS; Milthorpe BK; Besenbacher F Monitoring cell adhesion on tantalum and oxidised polystyrene using a quartz crystal microbalance with dissipation. Biomaterials 2006, 27, 4529-4537. [PubMed: 16716396]

(23). Redepenning J; Schlesinger TK; Mechalke EJ; Puleo DA; Bizios R Osteoblast attachment monitored with a quartz crystal microbalance. Anal. Chem 1993, 65, 3378-3381. [PubMed: 8297027]

(24). Gryte D,M; Michael DW; Wei-Shou H Real-Time Measurement of Anchorage-Dependent Cell Adhesion Using a Quartz Crystal Microbalance. Biotechnol. Progr 1993, 9, 105-108.

(25). Wegener J; Janshoff A; Galla HJ Cell adhesion monitoring using a quartz crystal microbalance: comparative analysis of different mammalian cell lines. Eur. Biophys. J 1998, 28, 26-37.

(26). Modin C; Stranne A-L; Foss M; Duch M; Justesen J; Chevallier J; Andersen LK; Hemmersam AG; Pedersen FS; Besenbacher F QCM-D studies of attachment and differential spreading of pre-osteoblastic cells on Ta and Cr surfaces. Biomaterials 2006, 27, 1346-1354. [PubMed: 16236355]

(27). Wegener J; Seebach J; Janshoff A; Galla H-J Analysis of the Composite Response of Shear Wave Resonators to the Attachment of Mammalian Cells. Biophys. J 2000, 78, 2821-2833. [PubMed: 10827965]

(28). Rodahl M; Hook F; Fredriksson C; Keller CA; Krozer A; Brzezinski P; Voinova M; Kasemo B Simultaneous frequency and dissipation factor QCM measurements of biomolecular adsorption and cell adhesion. Faraday Discuss. 1997, 229-246. [PubMed: 9569776]

(29). Fredriksson C; Kihlman S; Rodahl M; Kasemo B The Piezoelectric Quartz Crystal Mass and Dissipation Sensor: A Means of Studying Cell Adhesion. Langmuir 1998, 14, 248-251.

(30). Marx KA; Zhou T; Montrone A; McIntosh D; Braunhut SJ Quartz crystal microbalance biosensor study of endothelial cells and their extracellular matrix following cell removal: Evidence for 
transient cellular stress and viscoelastic changes during detachment and the elastic behavior of the pure matrix. Anal. Biochem 2005, 343, 23-34. [PubMed: 15979557]

(31). Molino PJ; Hodson OM; Quinn JF; Wetherbee R The Quartz Crystal Microbalance: a New Tool for the Investigation of the Bioadhesion of Diatoms to Surfaces of Differing Surface Energies. Langmuir 2008, 24, 6730-6737. [PubMed: 18507412]

(32). Saravia V; Toca-Herrera JL Substrate influence on cell shape and cell mechanics: HepG2 cells spread on positively charged surfaces. Microsc. Res. Tech 2009, 72, 957-964. [PubMed: 19484748]

(33). Fredriksson C; Khilman S; Kasemo B; Steel DM In vitro real-time characterization of cell attachment and spreading. J. Mater. Sci. Mater. Med 1998, 9, 785-788. [PubMed: 15348940]

(34). Fohlerová Z; Skládal P; Turánek J Adhesion of eukaryotic cell lines on the gold surface modified with extracellular matrix proteins monitored by the piezoelectric sensor. Biosens. Bioelectron 2007, 22, 1896-1901. [PubMed: 16979332]

(35). Amorim S; Pires RA; Costa D. S. d.; Reis RL; Pashkuleva I Interactions between Exogenous FGF-2 and Sulfonic Groups: in Situ Characterization and Impact on the Morphology of Human Adipose-Derived Stem Cells. Langmuir 2013, 29, 7983-7992. [PubMed: 23725085]

(36). Araújo AR; Soares da Costa D; Amorim S; Reis RL; Pires RA; Pashkuleva I Surfaces Mimicking Glycosaminoglycans Trigger Different Response of Stem Cells via Distinct Fibronectin Adsorption and Reorganization. ACS Appl. Mater. Interfaces 2016, 8, 28428-28436. [PubMed: 27714997]

(37). Zhang S; Bai H; Yang P Real-time monitoring of mechanical changes during dynamic adhesion of erythrocytes to endothelial cells by QCM-D. Chem. Commun 2015, 51, 11449-11451.

(38). Zhou T; Marx KA; Dewilde AH; McIntosh D; Braunhut SJ Dynamic cell adhesion and viscoelastic signatures distinguish normal from malignant human mammary cells using quartz crystal microbalance. Anal. Biochem 2012, 421, 164-171. [PubMed: 22119070]

(39). Chen JY; Shahid A; Garcia MP; Penn LS; Xi J Dissipation monitoring for assessing EGFinduced changes of cell adhesion. Biosens. Bioelectron 2012, 38, 375-381. [PubMed: 22770828]

(40). Garcia MP; Shahid A; Chen JY; Xi J Evaluating inhibition of the EGF-induced response of mutant MCF10A cells with an acoustic sensor. Biosensors 2012, 2, 448-464. [PubMed: 25586035]

(41). Berrier AL; Yamada KM Cell-matrix adhesion. J. Cell. Physiol 2007, 213, 565-573. [PubMed: 17680633]

(42). Juliano RL Signal transduction by cell adhesion receptors and the cytoskeleton: Functions of Integrins, Cadherins, Selectins, and Immunoglobulin-Superfamily Members. Annu. Rev. Pharmacool. Toxicol 2002, 42, 283-323.

(43). Balaban NQ; Schwarz US; Riveline D; Goichberg P; Tzur G; Sabanay I; Mahalu D; Safran S; Bershadsky A; Addadi L; Geiger B Force and focal adhesion assembly: a close relationship studied using elastic micropatterned substrates. Nat. Cell Biol. 2001, 3, 466-472. [PubMed: 11331874]

(44). Beningo KA; Dembo M; Kaverina I; Small JV; Wang Y.-1. Nascent Focal Adhesions Are Responsible for the Generation of Strong Propulsive Forces in Migrating Fibroblasts. J. Cell Biol. 2001, 153, 881-888. [PubMed: 11352946]

(45). Gallant ND; Michael KE; García AJ Cell Adhesion Strengthening: Contributions of Adhesive Area, Integrin Binding, and Focal Adhesion Assembly. Mol. Biol. Cell 2005, 16, 4329-4340. [PubMed: 16000373]

(46). Tan JL; Tien J; Pirone DM; Gray DS; Bhadriraju K; Chen CS Cells lying on a bed of microneedles: an approach to isolate mechanical force. Proc. Natl. Acad. Sci. U. S. A 2003, 100, 1484-1489. [PubMed: 12552122]

(47). Ellis JS; Thompson M Viscoelastic modeling with interfacial slip of a protein monolayer electrode-adsorbed on an acoustic wave biosensor. Langmuir 2010, 26, 11558-11567. [PubMed: 20394431]

(48). Voinova MV; Rodahl M; Jonson M; Kasemo B Viscoelastic acoustic response of layered polymer films at fluid-solid interfaces: Continuum mechanics approach. Phys. Scr 1999, 59, 391-396. 
(49). Johannsmann D Studies of Viscoelasticity with the QCM. Springer Ser Chem Se 2007, 5, 49109.

(50). Kanazawa KK Some basics for operating and analyzing data using the thickness shear mode resonator. Analyst 2005, 130, 1459-1464. [PubMed: 16222364]

(51). Ellis JS; Thompson M Acoustic physics of surface-attached biochemical species. HFSP J. 2008, 2, 171-177. [PubMed: 19404427]

(52). Kollmannsberger P; Fabry B Active soft glassy rheology of adherent cells. Soft Matter 2009, 5, 1771.

(53). Schmitz J; Gottschalk K-E Mechanical regulation of cell adhesion. Soft Matter 2008, 4, 1373.

(54). Voinova MV; Jonson M; Kasemo B On dissipation of quartz crystal microbalance as a mechanical spectroscopy tool. Spectrosc-Int J 2004, 18, 537-544.

(55). Evans E Probing the Relation Between Force-Lifetime-and Chemistry in Single Molecular Bonds. Annu. Rev. Biophys. Biomol. Struct 2001, 30, 105-128. [PubMed: 11340054]

(56). Evans EA; Calderwood DA Forces and Bond Dynamics in Cell Adhesion. Science 2007, 316, 1148-1153. [PubMed: 17525329]

(57). Aratyn-Schaus Y; Gardel ML Transient Frictional Slip between Integrin and the ECM in Focal Adhesions under Myosin II Tension. Curr. Biol 2010, 20, 1145-1153. [PubMed: 20541412]

(58). Verkhovsky AB Cell-Matrix Adhesion: Slip and Immobilization under Force. Curr. Biol 2010, 20, R669-R671. [PubMed: 20728050]

(59). Bell GI Models for the specific adhesion of cells to cells. Science 1978, 200, 618-627. [PubMed: 347575]

(60). Bell GI; Dembo M; Bongrand P Cell adhesion. Competition between nonspecific repulsion and specific bonding. Biophys. J 1984, 45, 1051-1064. [PubMed: 6743742]

(61). Ellis JS; Thompson M Acoustic coupling at multiple interfaces and the liquid phase response of the thickness shear-mode acoustic wave sensor. Chem. Comm 2004.

(62). Huang K; Szlufarska I Friction and Slip at the Solid/Liquid Interface in Vibrational Systems. Langmuir 2012, 28, 17302-17312. [PubMed: 23157613]

(63). Ferrante F; Kipling AL; Thompson M Molecular slip at the solid-liquid interface of an acousticwave sensor. J. Appl. Phys 1994, 76, 3448-3462.

(64). Rodahl M; Hook F; Kasemo B QCM Operation in Liquids: An Explanation of Measured Variations in Frequency and Q Factor with Liquid Conductivity. Anal Chem 1996, 68, 2219 2227. [PubMed: 21619308]

(65). Rodahl M; Kasemo B On the measurement of thin liquid overlayers with the quartz-crystal microbalance. Sensor Actuat a-Phys 1996, 54, 448-456.

(66). Filippov AE; Klafter J; Urbakh M Friction through dynamical formation and rupture of molecular bonds. Phys. Rev. Lett 2004, 92.

(67). Li DC; Ji BH Predicted Rupture Force of a Single Molecular Bond Becomes Rate Independent at Ultralow Loading Rates. Phys. Rev. Lett 2014, 112.

(68). Dong C; Lei XX Biomechanics of cell rolling: shear flow, cell-surface adhesion, and cell deformability. J. Biomechanics 2000, 33, 35-43.

(69). Kong D; Ji BH; Dai LH Stability of adhesion clusters and cell reorientation under lateral cyclic tension. Biophys. J 2008, 95, 4034-4044. [PubMed: 18621806]

(70). Garcia MP; Shahid A; Chen JY; Xi J Effects of the expression level of epidermal growth factor receptor on the ligand-induced restructuring of focal adhesions: a QCM-D study. Anal Bioanal Chem 2013, 405, 1153-1158. [PubMed: 23180089]

(71). Li F; Wang JHC; Wang Q-M Thickness shear mode acoustic wave sensors for characterizing the viscoelastic properties of cell monolayer. Sens. Actuators B Chem. 2008, 128, 399-406.

(72). Marxer CG; Coen M; Bissig H; Greber U; Schlapbach L Simultaneous measurement of the maximum oscillation amplitude and the transient decay time constant of the QCM reveals stiffness changes of the adlayer. Anal. Bioanal. Chem 2003, 377, 570-577. [PubMed: 14504678]

(73). Marxer CG; Collaud Coen M; Greber T; Greber U; Schlapbach L Cell spreading on quartz crystal microbalance elicits positive frequency shifts indicative of viscosity changes. Anal. Bioanal. Chem 2003, 377, 578-586. [PubMed: 12879196] 
(74). Yang RG; Chen JY; Xi N; Lai KWC; Qu CG; Fung CKM; Penn LS; Xi J Characterization of mechanical behavior of an epithelial monolayer in response to epidermal growth factor stimulation. Exp. Cell Res. 2012, 318, 521-526. [PubMed: 22227009]

(75). Pellegrin S; Mellor H Actin stress fibres. J. Cell Sci. 2007, 120, 3491-3499. [PubMed: 17928305]

(76). Tymchenko N; Nilebäck E; Voinova M; Gold J; Kasemo B; Svedhem S Reversible Changes in Cell Morphology due to Cytoskeletal Rearrangements Measured in Real-Time by QCM-D. Biointerphases 2012, 7, 1-9. [PubMed: 22589044]

(77). Maheshwari G; Brown G; Lauffenburger DA; Wells A; Griffith LG Cell adhesion and motility depend on nanoscale RGD clustering. J. Cell Sci. 2000, 113 ( Pt 10), 1677-1686. [PubMed: 10769199]

(78). Sawada Y; Sheetz MP Force transduction by Triton cytoskeletons. J. Cell Biol. 2002, 156, 609615. [PubMed: 11839769]

(79). ChrzanowskaWodnicka M; Burridge K Rho-stimulated contractility drives the formation of stress fibers and focal adhesions. J. Cell Biol. 1996, 133, 1403-1415. [PubMed: 8682874]

(80). Khalili A; Ahmad M A Review of Cell Adhesion Studies for Biomedical and Biological Applications. Int. J. Mole. Sci 2015, 16, 18149.

(81). Dembo M; Wang Y-L Stresses at the Cell-to-Substrate Interface during Locomotion of Fibroblasts. Biophys. J 1999, 76, 2307-2316. [PubMed: 10096925]

(82). Walcott S; Sun SX A mechanical model of actin stress fiber formation and substrate elasticity sensing in adherent cells. Proc. Natl. Acad. Sci. U. S. A 2010, 107, 7757-7762. [PubMed: 20385838]

(83). Maraldi M; Valero C; Garikipati K A computational study of stress fiber-focal adhesion dynamics governing cell contractility. Biophys. J 2014, 106, 1890-1901. [PubMed: 24806921]

(84). Deshpande VS; McMeeking RM; Evans AG A bio-chemo-mechanical model for cell contractility. Proc. Natl. Acad. Sci. U. S. A 2006, 103, 14015-14020. [PubMed: 16959880]

(85). Fang Y Label-free receptor assays. Drug Discovery Today: Technol. 2010, 7, e5-e11.

(86). Cooper MA Non-optical screening platforms: the next wave in label-free screening? Drug Discovery Today 2006, 11, 1068-1074. [PubMed: 17129825]

(87). Cooper MA Optical biosensors: where next and how soon? Drug Discovery Today 2006, 11, 1061-1067. [PubMed: 17129824]

(88). Rocheville M; Jerman JC 7TM pharmacology measured by label-free: a holistic approach to cell signalling. Current Opinion in Pharmacology 2009, 9, 643-649. [PubMed: 19671497]

(89). Le Guillou-Buffello D; Gindre M; Johnson P; Laugier P; Migonney V An alternative quantitative acoustical and electrical method for detection of cell adhesion process in real-time. Biotechnol Bioeng 2011, 108, 947-962. [PubMed: 21404267] 


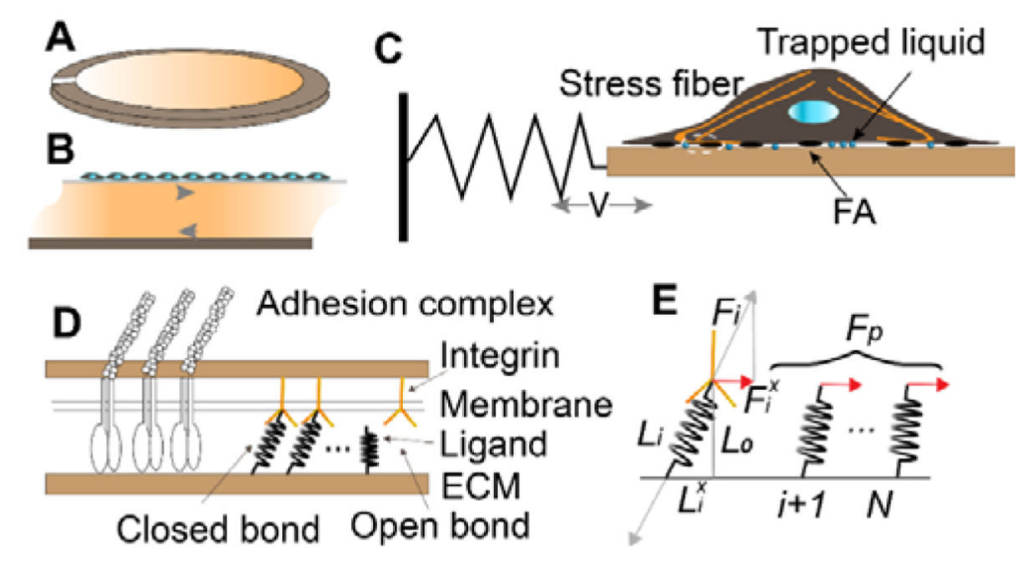

Figure 1. Biomechanical model of the cell-adhered QCM-D.

(A) A QCM-D sensor disk. (B) The shear motion of the cell-adhered QCM-D sensor disk.

(C) The cell-adhered QCM-D sensor is modeled as a harmonic oscillator driven horizontally by a spring. The trapping of the liquid by the cell and the adhesion of the cell via focal adhesions and stress fibers are illustrated. (D) The dynamic restructuring of integrin-ECM bonds is modeled as an ensemble of elastic springs with open and closed states. (E) The forces in relation to distances in a closed bond are defined: $F_{i}$ as the bond force in the $i$ th adhesion bond, $F_{i}^{x}$ as the peeling force $F_{p}$ in the -x direction, $L_{i}$ as the length of the $i$ bond, and $L_{0}$ as the natural length of an integrin-ECM bond. 


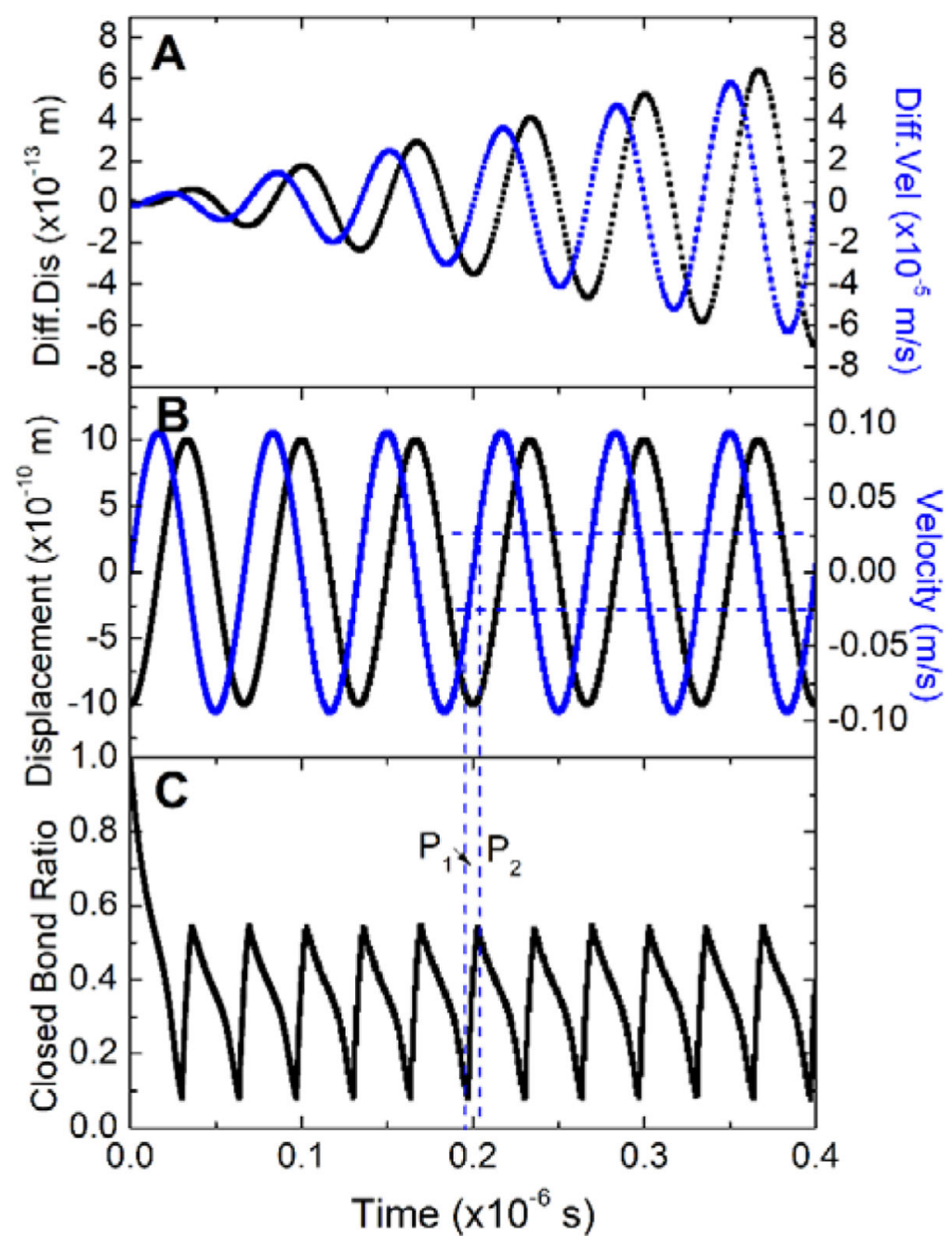

Figure 2. Dynamics of a damped oscillating sensor disk.

(A) Time-dependent changes of the respective difference of displacement (black) and velocity (blue) between a damped oscillation and an undamped oscillation. The oscillation amplitude is between $-1 \mathrm{~nm}$ and $1 \mathrm{~nm}$ and the observation time is $5 \mu$ s (The initial period of $0.4 \mu \mathrm{s}$ is shown). (B) Time-dependent changes of the damped displacement (black) and velocity (blue) of one oscillation cycle. (C) Time-dependent change of the closed bond ratio during the same time period. The profile shows two distinct phases: the low-velocity $V<V_{c}$ $\left(V_{c}=0.025 \mathrm{~m} / \mathrm{s}\right)$ in which the bond formation process dominates $\left(\mathrm{P}_{1}\right)$; the stick-slip regime in which the synchronized bond rupture is clearly visible $\left(\mathrm{P}_{2}\right)$. All calculations were performed at bond number $\mathrm{N}=10^{10}$ at a time step of $10^{-12} \mathrm{~s}$ over an observation time period of $5 \mu \mathrm{s}$. 


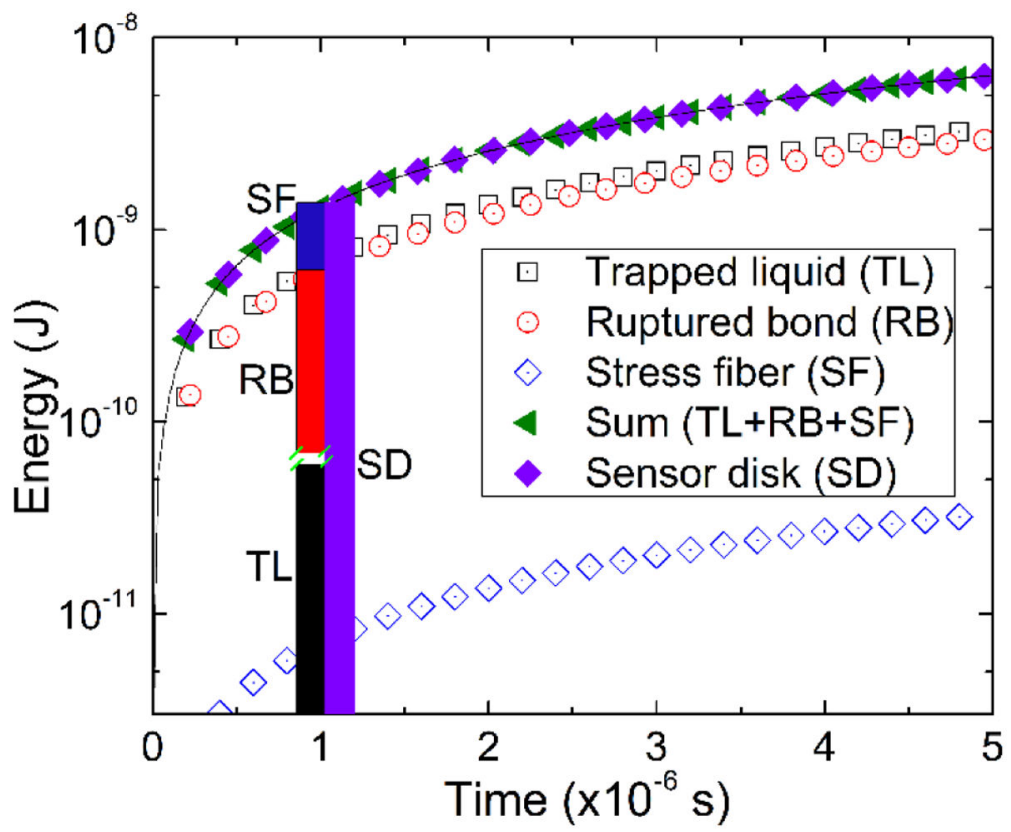

Figure 3. Time-dependent energy dissipation of the three dissipative processes and loss of the mechanical energy of the sensor disk.

Among the three processes, stress fiber (SF) related damping dissipates the least amount of energy, which is approximately two orders of magnitude less than the amount of energy dissipated by the trapped liquid (TL) or ruptured bond (RB) related process. The stackedcolumn chart shows that at a randomly selected time point $1 \mu \mathrm{s}$, the loss of the mechanical energy of the oscillating sensor disk (SD) equals the sum of the energies dissipated from the three dissipative processes $(\mathrm{SF}+\mathrm{RB}+\mathrm{TL})$. All calculations were performed at bond number $\mathrm{N}=10^{10}$ at a time step of $10^{-12}$ s over an observation time period of $5 \mu$ s. 

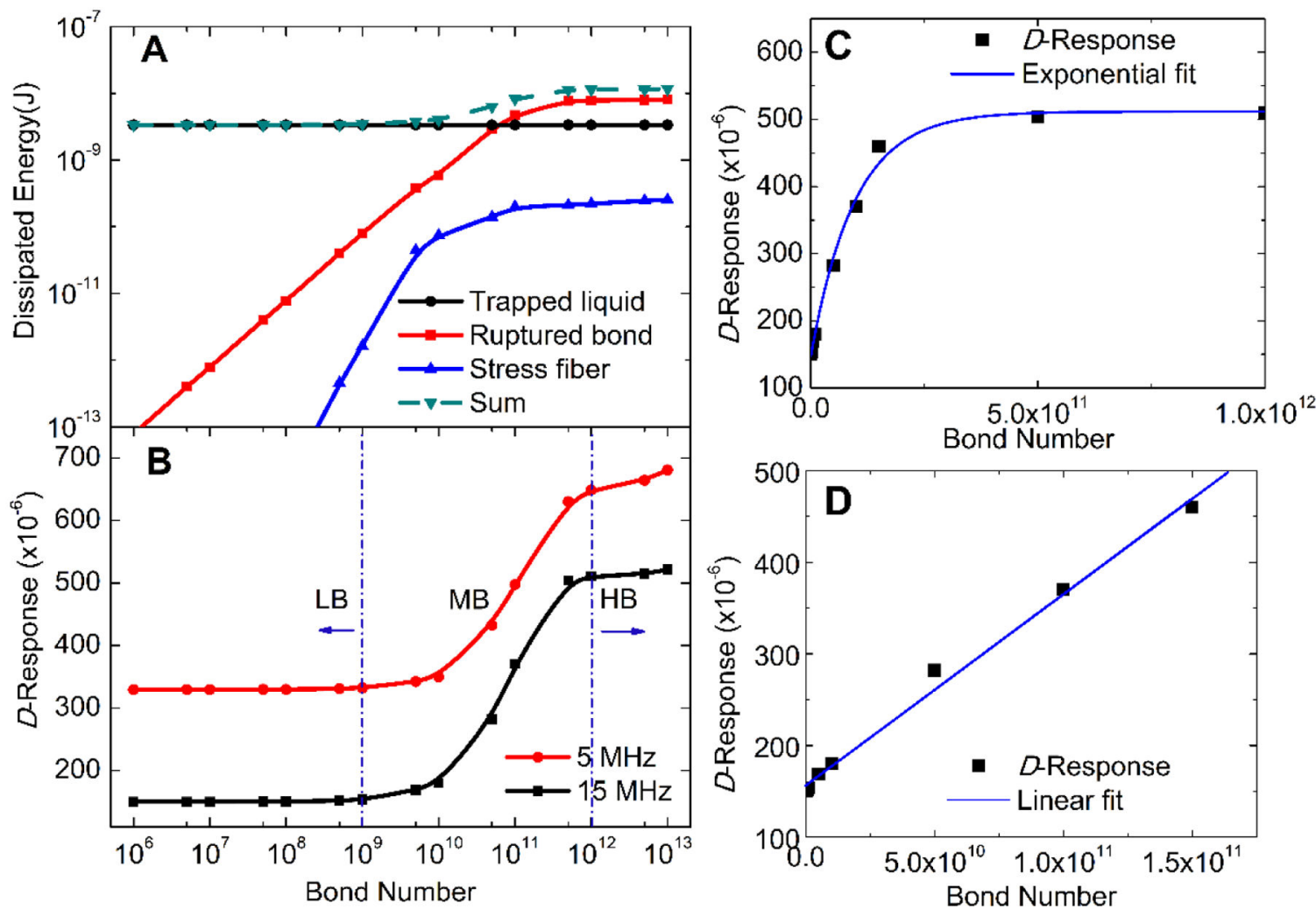

Figure 4. Energy dissipation from the three dissipative processes as a function of number of cellECM bonds.

(A) Respective contributions from bond rupture, trapped liquid, and stress fibers related damping to the energy dissipation as a log function of the bond number. (B) $D$-response as a $\log$ function of bond number at the fundamental frequency $(5 \mathrm{MHz})$ and the third harmonic $(15 \mathrm{MHz})$. Three distinct phases of the profile are defined based on the bond number: the low bond number region (LB), medium bond number region (MB) and high bond number region (HB). (C) D-response at the third harmonic as an exponential function of bond number. (D) $D$-response at the third harmonic as a linear function of bond number. 

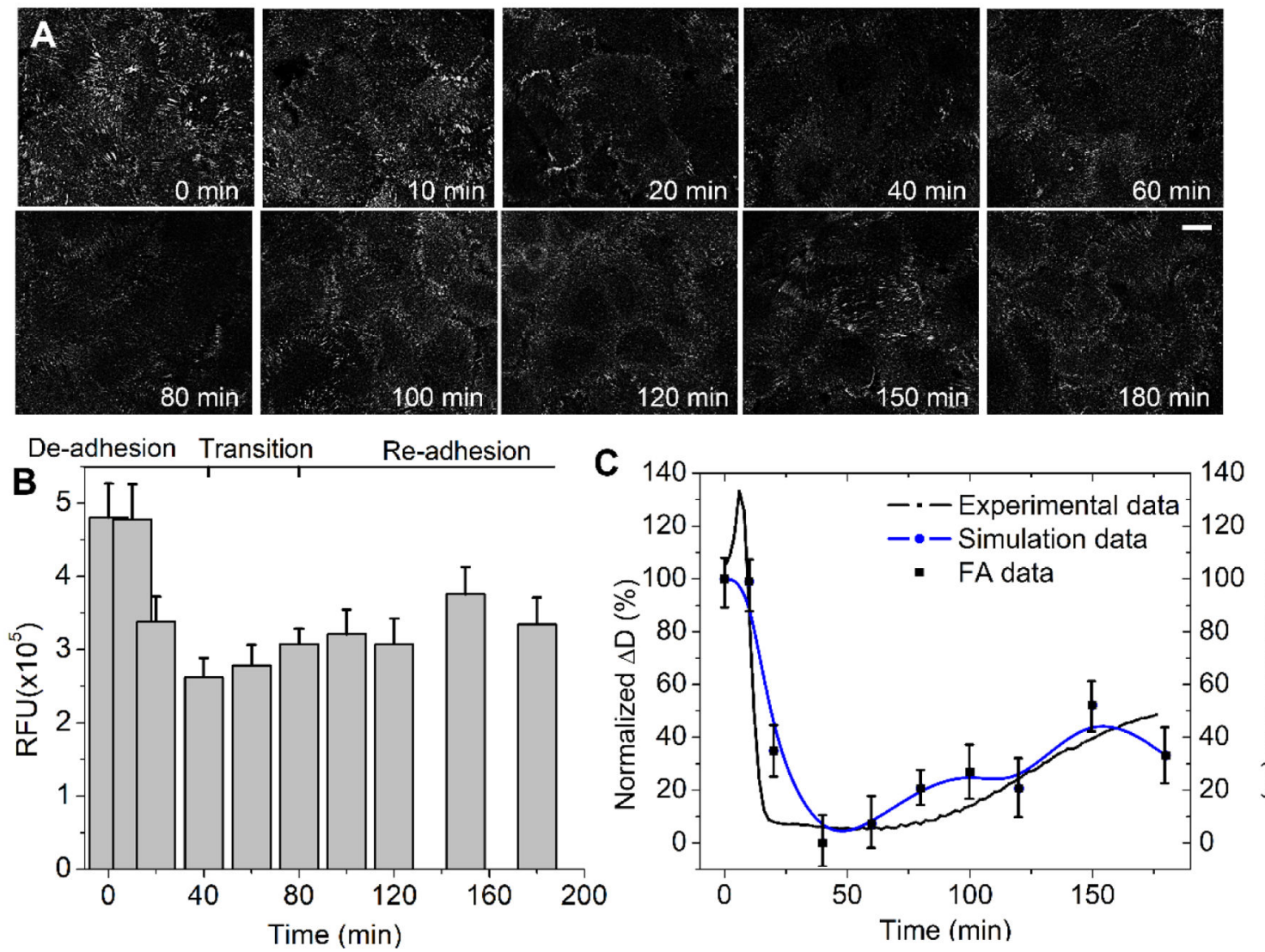

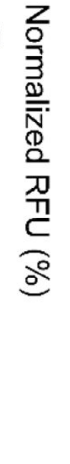

Figure 5. The correlation between the $\Delta D$-response and the level of focal adhesions.

(A) Fluorescence images of focal adhesions in a monolayer of A431 cells after various lengths of time of exposure to $10 \mathrm{nM}$ EGF. Scale bar: $10 \mu \mathrm{m}$. (B) Quantitation of the areal density of immunostained vinculin in relative fluorescence unit (RFU) as a measure for the level of focal adhesions (mean $\pm \mathrm{SEM} ; \mathrm{n}=10$ ). (C) The $\Delta D$-response from the QCM-D measurement (Experimental data) shows a strong correlation with the simulated $\Delta D$ response (Simulation data) as well as the areal density of focal adhesions (FA data). 